This is the peer reviewed version of the following article: Micai, M. , Joseph, H. , Vulchanova, M. and Saldaña, D. (2017), Strategies of readers with autism when responding to inferential questions: An eye-movement study. Autism Research, 10: 888900. doi:10.1002/aur.1731 which has been published in final form at https://doi.org/10.1002/aur.1731. This article may be used for non-commercial purposes in accordance with Wiley Terms and Conditions for Self-Archiving. 


\title{
Strategies of Readers With Autism When Responding to Inferential Questions: An Eye-Movement Study
}

\author{
Martina Micai, Holly Joseph, Mila Vulchanova, and David Saldaña
}

\begin{abstract}
Previous research suggests that individuals with autism spectrum disorder (ASD) have difficulties with inference generation in reading tasks. However, most previous studies have examined how well children understand a text after reading or have measured on-line reading behavior without response to questions. The aim of this study was to investigate the online strategies of children and adolescents with autism during reading and at the same time responding to a question by monitoring their eye movements. The reading behavior of participants with ASD was compared with that of age-, language-, nonverbal intelligence-, reading-, and receptive language skills-matched participants without ASD (control group). The results showed that the ASD group were as accurate as the control group in generating inferences when answering questions about the short texts, and no differences were found between the two groups in the global paragraph reading and responding times. However, the ASD group displayed longer gaze latencies on a target word necessary to produce an inference. They also showed more regressions into the word that supported the inference compared to the control group after reading the question, irrespective of whether an inference was required or not. In conclusion, the ASD group achieved an equivalent level of inferential comprehension, but showed subtle differences in reading comprehension strategies compared to the control group. Autism Res 2016, 0: 000-000. ( 2016 International Society for Autism Research, Wiley Periodicals, Inc.
\end{abstract}

Keywords: autism spectrum disorder; inference; reading; language; eye movement

\section{Introduction}

The influential model of reading comprehension proposed by Van Dijk and Kintsch [1983; Kintsch \& Rawson, 2005] is characterized by two interactive levels of comprehension: a text based or propositional representation, which includes comprehension involving a simple linguistic representation (e.g., word decoding), and a situation model or mental model that connects information and organizes it globally in a larger structure which also includes prior knowledge. When the information in the text is not directly connected, the reader may need to generate an inference in order to build a coherent situation model. During this process, the user fills in the missing links and creates a coherent flow of meaning units integrating them in the prior knowledge background [Kintsch \& Van Dijk, 1978]. The present study aimed to explore the ability of individuals with autism to make inferences which underlie the creation of situation models and, as such, have been shown to be essential for reading comprehension [Cain, Oakhill, Barnes, \& Bryant, 2001] and discourse comprehension [Snyder \& Caccamise, 2010].
Among the clinical populations that show difficulties in reading comprehension [see, e.g., Cain \& Bignell, 2014, and Miller et al., 2013, for an example in Attention Deficit Hyperactivity Disorder], autism is one of the most extensively researched [Ricketts, 2011]. Several studies have shown that, in particular, inference generation is impaired in autism. Initially, this impairment was observed as a difficulty in inferring the adequate meaning of a homograph [Frith \& Snowling, 1983; Happé, 1997]. More recently, Jolliffe and Baron-Cohen [1999a, 2000] reported difficulties in global coherence, exploring sentence rearrangement and global inference generation. They also found difficulties in achieving local coherence, using a homograph integration task, a task involving the generation of bridging inferences and a task for ambiguous sentence interpretation [Jolliffe \& Baron-Cohen, 1999b]. Later, Norbury and Bishop [2002], applying a categorical examination, showed inferencing deficits in individuals with pragmatic difficulties related to high-functioning autism. In addition, a strong relationship between story comprehension and recall was observed, showing that individuals who had

From the Department of Developmental and Educational Psychology, Universidad de Sevilla, Seville, Spain (M.M., D.S.,); Department of Language and Literature, Norwegian University of Science and Technology, Trondheim, Norway (M.M., M.V.,); Institute of Education, University of Reading, Reading, UK (H.J.)

Received April 25, 2016; accepted for publication November 11, 2016

Address for correspondence and reprints: Martina Micai, Department of Developmental and Educational Psychology, Universidad de Sevilla, C/Camilo José Cela s/n, Seville 41018, Spain. E-mail: mmicai@us.es

Published online 00 Month 2016 in Wiley Online Library (wileyonlinelibrary.com)

DOI: 10.1002/aur.1731

(C) 2016 International Society for Autism Research, Wiley Periodicals, Inc. 
higher scores in comprehension also performed better in recall.

However, other research has shown similar levels of reading comprehension skills in individuals with autism and typically developing (TD) readers [LaPointe-Speer, 2007; Mayes \& Calhoun, 2003, 2008; Sansosti, Was, Rawson, \& Remaklus, 2013]. It seems that individuals with autism spectrum disorders (ASD) may reach the same level of comprehension as typical readers under specific conditions. Reading studies in ASD vary considerably in the nature of the task administered and in participants' oral and language-related skills. Contradictory results in this field have sometimes been related to the use of off-line (i.e., question answering) or more online (usually response or reading time) measures, with greater differences typically appearing more in the off-line tasks [Jolliffe \& BaronCohen, 2000; Nation et al., 2006; Norbury \& Bishop, 2002], than in response time measures [Saldaña \& Frith, 2007; Sansosti et al., 2013; Tirado \& Saldaña, 2015]. An exception to this appears in studies using eye-tracking. Sansosti et al. [2013], e.g., found that while readers with autism showed similar accuracy and reaction times in responding to questions as a control group on a task requiring bridging inferences, they spent more time fixating the text, and made more fixations and regressions than the TD readers. Subtle differences in reading behavior have also recently been found by Howard, Liversedge, and Benson [2016], whose participants with autism made more regressions in a sentence reading task than controls. However, in their case the task did not require the production of inferences, and their results are unlikely to relate to problems in inferencing itself. In any case, these eyemovement studies seem to indicate that the way in which readers with autism reach the same endpoint during text comprehension could be different and sensitive eyetracking measures may help to uncover these different underlying processes.

The current study was designed to explore spontaneous elaborative inference making [McKoon \& Ratcliff, 1992] during reading by monitoring participants' eye movements as they read texts that did, or did not require the generation of inferences. Monitoring a reader's eye movements gives an extremely accurate and detailed index of which words or phrases a reader is finding particularly difficult to process [Rayner, 1998], and thus permits the extraction of information about the time course in which disruption to processing occurs, and what the reader does on encountering difficulty [Vasishth, von der Malsburg, \& Engelmann, 2012]. In addition, eye-movement data have been shown to be sensitive to global text passage difficulty and inconsistency in texts [Rayner, 2009]. Furthermore, eye-movement data should provide us with an accurate insight into how inference-making unfolds in persons with ASD when they have to respond to a question about a text.
We also aimed to closely match participants on variables that have been shown to predict text comprehension. In particular, it is important to consider the oral language profile in individuals with ASD, because it has consistently been found to be a predictor of reading comprehension in general [Norbury \& Nation, 2011; Ricketts, Jones, Happé, \& Charman, 2013], interpretative language ability [Minshew, Goldstein, \& Siegel, 1995], use of linguistic context [Eberhardt \& Nadig, 2016], and inferencing skill [Lucas \& Norbury, 2015]. It has been suggested that differences in reading comprehension between autism and control groups found in many studies could disappear with improved matching [Norbury \& Bishop, 2002]. For this reason, we included in the study individuals with high functioning autism displaying similar standardized receptive language, reading comprehension and fluency scores as our group of children and adolescents without ASD (control group). The sample of individuals recruited for this study may be not representative of the full scale of the autism spectrum, in that they are highly verbal and high functioning. However, we consider it important to control for factors that have been observed to influence inferencing skill (e.g., structural language skills) and to study inferencing in the absence of impaired language in a sample of individuals that did not differ from controls on a relatively important number of background variables and in the presence of autistic symptomatology.

Against this back drop, our study first aimed to explore whether there were any differences in accuracy in responding to inferential questions (inference condition) compared to questions requiring factual understanding (literal condition) between individuals with and without ASD matched on age, nonverbal intelligence scores, language, and reading skills.

Second, our study aimed to explore global paragraph reading behavior, as well as question-answering time while reading the texts and responding to the questions. Given the on-line nature of the task and the high cognitive and language skills of our clinical group, we expected no differences between the two groups in accuracy or global eye-movement measures while reading the text and answering the questions.

Finally, we conducted some more fine-grained analyses in order to investigate eye-movement behavior on predefined target words related to the paragraph assigned to the literal and inferential condition in the experimental texts in our two groups of participants. We expected to see a difficulty in the integration of the target word that supported the inference in the situation model that would translate into slower reading times in the inferential condition in the ASD participants compared to the control group [Cook \& Myers, 2004; Garrod \& Terras, 2000; O’Brien, Shank, Myers, \& Rayner, 1988]. This disruption of the integration of the target 


\begin{tabular}{lcccc}
\hline & \multicolumn{2}{c}{ ASD $(n=22)$} & & \multicolumn{2}{c}{ Control $(n=22)$} \\
\cline { 2 - 3 } & Mean (SD) & Range & Mean (SD) & Range \\
\hline Perceptual Reasoning Index & $107(18)$ & $74-134$ & $108(14)$ & $81-139$ \\
Working Memory Index & $107(16)$ & $79-137$ & $106(12)$ & .85 \\
PPVT-III (Standardized Scores) & $107(18)$ & $66-135$ & $110(12)$ & .81 \\
CEG (Raw Scores) & $73(3)$ & $66-79$ & $75(2)$ & $80-134$ \\
TALE Reading Speed (Words) & $125(35)$ & $63-181$ & $141(30)$ & $68-80$ \\
$\quad$ Seconds Raw Scores) & $57(16)$ & $28-100$ & $65(20)$ & $80-195$ \\
TALE Reading Comprehension & & & .62 \\
$\quad$ accuracy (\% Raw Scores) & & & .14 \\
\end{tabular}

$n=$ number of participants; PPVT-III = Peabody Picture Vocabulary Test - Third Edition; CEG = Grammatical Structures Comprehension Test; TALE $=$ Magellan Scales of Reading and Writing.

word into a coherent situation model was also expected to result in a higher number of eye movements such as regressions in the inferential condition for the ASD group [Sansosti et al., 2013]. However, we expected that early processing eye-movement measures (i.e., first and single fixation durations) of the target word to be comparable between ASD and control groups, given the expectation of intact lexical processing. Early processing eye-movement measures refer to the first-pass measures that occur prior to any regression back to the word and are found to be informative of a word's representation, orthography, phonology, or meaning [Juhasz \& Pollatsek, 2011]. Exploratory analyses were also conducted in order to distinguish general integration processes from those related to the task of answering the question itself, by comparing the percentage of regressions coming from the part of the text that followed the target word with the percentage of regressions coming from the question. This analysis was possible since both text and question were present on the screen at the same time. Additionally, the target word was present in each paragraph with other three critical words that changed depending on the paragraph condition (inferential and literal). We explored reading behavior also in relation to these critical words present in the text. One of the critical words provided the correct answer to the literal question in a literal condition, and the others were filler words. We expected to find similar reading behavior for these categories of words between the two groups, since none of them involved inferencing, showing that reading behavior in ASD may be atypical only during the situation model integration, rather than during the overall process of reading.

\section{Method}

Participants

Thirty-four children and adolescents with a diagnosis of autism spectrum disorder or Asperger's syndrome were recruited from local autism associations. Individuals with comorbidity with other developmental and acquired disorders or vision problems that impede reading, or bilingual families, were excluded from recruitment. Diagnoses were confirmed by a trained psychologist, using the Autism Diagnostic Observation Schedule [ADOS; Lord et al., 2000]. All participants met the clinical cutoff on the ADOS with a total score $>7$ (mean $=11.4$, range $=7-16)$.

A control group of 36 native Spanish children and adolescents was recruited from local schools of middle-class neighborhoods. Exclusion criteria were the same as for the autism group. Three ASD participants were excluded because of low scores on nonverbal intelligence, defined as Perceptual Reasoning Index (PRI) and Working Memory Index (WMI) below or equal to 70. During the matching process, in which the ASD and control sample were statistically matched on chronological age (ASD mean age $=12.6$ years, $\mathrm{SD}=2.5$, range $=9.9-17.2$; control group mean age $=13, \mathrm{SD}=2.5$, range 9.4-17.8; $P=.11$ ), gender (ASD: 3 females; control group: 7 females, $P=.25$ ), nonverbal IQ, raw scores on grammatical structure comprehension, vocabulary size, reading speed, and comprehension accuracy, a further 9 participants with ASD and 14 controls were excluded, leaving a final sample of 44 individuals, all monolingual Spanish speakers from Andalucía in the south of Spain (ASD: $n=22$; controls: $n=22$ ). No statistical differences existed between groups on any matching variables (see Table 1 ).

The Andalusian Regional Biomedical Research Ethics board approved recruitment and data collection procedures. Written informed consent was obtained from participants' parents or legal guardians prior to any testing.

\section{Background Assessment \\ Nonverbal Intelligence}

The PRI and WMI subscales from the Wechsler Intelligence Scale for Children - Fourth Edition [WISC-IV; Wechsler, 2005] or Wechsler Adult Intelligence Scale - Fourth Edition [WAIS-IV; Wechsler, 2012] were used, depending on the participant's age, to assess nonverbal intellectual ability. 
Receptive Language

Receptive vocabulary size was measured using the Spanish version of the Peabody Picture Vocabulary Test - Third Edition [PPVT-III; Dunn, Dunn, \& Arribas, 2006]. Receptive grammar was assessed using the Grammatical Structures Comprehension Test [CEG; Mendoza, Carballo, Muñoz, \& Fresneda, 2005]. The CEG test is a Spanish version of the Test for Reception of Grammar for English [TROG; Bishop, 1983]. The CEG test shows a Cronbach's $\alpha=.91$. Its total scores correlate well with total scores from other tests such as PPVT-III $(r=.81, P<.001)$, Illinois Test of Psycholinguistic Abilities [ITPA; Kirk et al., 1968] $(r=.64, P<.001)$, and Digit Span from the Wechsler Intelligence Scale for Children Revised [WISC-R; Wechsler, 1999] $(r=.37 ; P=.003)$.

\section{Reading Skills}

The reading fluency and reading comprehension subtests of the Magellan Scales of Reading and Writing [EMLE TALE-2000; Toro, Cervera, \& Urío, 2002] were used to assess reading speed and reading comprehension, respectively. The reading fluency subtest requires reading aloud one of three age-appropriate texts. Numbers and types of decoding errors and reading times were recorded, although only reading time was included in the matching analysis. Each participant, depending on their level of schooling, read one of the three texts. The reading comprehension subtest consists in reading one of the three age-appropriate texts and answering multiplechoice questions. The EMLE TALE, which has a testretest reliability ranging from .76 to .85 , for different ages, has been shown to agree with teacher ratings in the identification of poor comprehenders in $98 \%$ of the cases, and has a Kappa of .68 for overall classification of readers into poor and good comprehenders.

\section{Apparatus}

Stimuli were presented on a 18.5 -inch monitor $(41 \times$ $23 \mathrm{~cm}$ ) connected to a computer interfaced with an EyeLink 1000 eye-tracker (SR Research, Ottawa, Ontario, Canada). The Eyelink 1000 is an infrared, video-based tracking system combined with hyperacuity image processing with a spatial resolution of 0.4 degrees, and a sampling rate of $1000 \mathrm{~Hz}$. While participants' viewing was binocular, only the movements of the right eye were recorded. Text was presented in black, Arial font size 20 on a light gray background. Participants were seated $55 \mathrm{~cm}$ from the monitor.

\section{Materials and Design \\ Paragraph Creation}

Five narrative stories in Spanish, divided into 30 paragraphs (6 per story), were created; at the end of each paragraph there was a question with three answer options. Each paragraph was presented with the corresponding question on a single screen. All paragraphs were 60 words long. We designed two versions of each paragraph, one which did not (literal condition) and one which did (inferential condition) require an inference to be made in order to answer the following question correctly. The paragraphs, questions and options in the two conditions were identical, except for one word: in the literal condition, a key word which enabled a correct response to the question without any need for an inference was present in the text (correct answer word, e.g., cat; Appendix 1). In the inferential condition the correct word was not present in the text, but replaced by another word (replacement word) that did not suggest the correct answer (e.g., little; Appendix 1). These words were matched on length and frequency [Real Academia Espaola, ] across conditions. In both conditions, a target word that allowed the participants to infer the correct answer (target word, e.g., mouse; Appendix 1), and a distractor word (e.g., parrot; Appendix 1) were also present.

A comprehension question was presented below the text with three possible responses. The response options were: (i) the correct answer (e.g., cat); (ii) a distractor that was present in the paragraph, but semantically distant from the correct option (In-text distractor; e.g., parrot), and (iii) a distractor that was absent in the text, but semantically close to the correct answer (Semantic distractor; e.g., dog). To permit the accurate analysis of eye-tracking data, the text was double spaced. The stories were developed such that minimal emotional [Bodner, Engelhardt, Minshew, \& Williams, 2015] and social understanding [White et al., 2009] were required.

\section{Norming Studies}

We prescreened all possible responses, target words, and distractors with TD children and adults who did not participate in the main experiment. The semantic proximity of the correct answer to the In-text distractor (e.g., parrot) and Semantic distractor (e.g., dog) was judged by 20 TD children (mean age $=12.4$, $\mathrm{SD}=0.6 ; 9$ females). In order to measure the semantic proximity for each correct option, four words were presented to the children. They were asked to judge which one was most different and which was most similar to the target word. We selected the words that the majority of the children judged to be similar (Semantic distractor) or different (In-text distractor) to the target. Second, 10 university students confirmed that, in the inferential paragraphs, the selected target word was the only word in the text useful to answer the question. Any changes to the defined target words were derived from this last evaluation. 
Table 2. Means (and SDs) of Accuracy and Global Eye Movement Data in Both, Inferential and Literal Conditions for ASD and Control Groups, and Overall Conditions Scores

\begin{tabular}{|c|c|c|c|c|c|c|}
\hline & \multicolumn{2}{|c|}{ ASD } & \multicolumn{2}{|c|}{ Control } & \multicolumn{2}{|c|}{ Both groups } \\
\hline & $\begin{array}{c}\text { Inferential } \\
n=22\end{array}$ & $\begin{array}{l}\text { Literal } \\
n=22\end{array}$ & $\begin{array}{c}\text { Inferential } \\
\quad n=22\end{array}$ & $\begin{array}{l}\text { Literal } \\
n=22\end{array}$ & $\begin{array}{c}\text { Inferential } \\
\quad n=44\end{array}$ & $\begin{array}{l}\text { Literal } \\
n=44\end{array}$ \\
\hline Percent correct & $89(10)$ & $95(4)$ & $84(15)$ & $95(7)$ & $87(13)^{* * *}$ & $95(6)$ \\
\hline $\begin{array}{l}\text { Paragraph reading/question } \\
\text { answering time }\end{array}$ & $31,472(13,730)$ & $28,224(11,459)$ & $27,581(10,559)$ & $24,957(8,511)$ & $29,527(12,263)^{* * *}$ & $26,590(10,111)$ \\
\hline Total number of fixations & $115(39)$ & $103(31)$ & $107(34)$ & $97(28)$ & $111(37)^{* * *}$ & $100(29)$ \\
\hline Average fixation duration & $211(35)$ & $210(37)$ & $210(28)$ & $209(29)$ & $210(32)$ & $209(33)$ \\
\hline Number of forward fixations & $61(27)$ & $59(27)$ & $56(25)$ & $59(24)$ & $58(25)$ & $59(25)$ \\
\hline Forward saccade length & $4.10(0.96)$ & $4.10(0.96)$ & $3.99(0.66)$ & $3.95(0.57)$ & $4.05(0.82)$ & $4.03(0.78)$ \\
\hline
\end{tabular}

Counterbalancing and Design

For both versions, fifteen paragraphs were assigned to the literal condition and 15 to the inferential condition. Each story contained three literal and three inferential paragraphs. The order of the three answer options was randomized and held constant across participants. The order of presentation of the five stories was randomized, whereas the order of the paragraphs within each story was held constant.

For each paragraph, the In-text distractor was always in the first or second sentence of the text, then, in the middle of the text, participants encountered the correct answer (only for the literal condition). Finally, the target word was always the 55th word in the paragraph. Prior to the presentation of the experimental trials, participants read and answered two practice trials (one literal and one inferential paragraph type) that were excluded from the final analysis.

\section{Procedure}

Standardized tests were administered in the following order to all participants: nonverbal intelligence, verbal skills, and reading abilities. The diagnosis confirmation tests were administered only to the ASD participants on a different day and prior to any testing. The participants completed the test assessment in two (control group) or three sessions (ASD group) of $1 \mathrm{hr}$ each on different nonconsecutive days. The eye-tracking experimental task was performed in a single 30-min session on a different day. Participants were tested individually, in a quiet room either in the university laboratory, at school, or at the local autism association. During eyetracking, chin and forehead rests were used to minimize head movements and ensure comfort. Participants undertook a nine-point calibration procedure. Participants then looked at a fixation point in the upper-left corner of the screen and the paragraph appeared contingent on their gaze. Subjects were asked to fixate on a fixation point in the left top of the screen prior to the presentation of each paragraph in order to check the calibration validity. If the fixation did not meet the criteria (maximum point error $<1.5$ degrees, average error $<1.0$ degrees) of accuracy, the participants were recalibrated. Participants were asked to read each paragraph silently and to answer questions by choosing one of the three possible responses which were displayed at the bottom of each paragraph, and to respond by choosing one of three alternatives via a key press. The beginning of a new story was advised by a screen showing the message "New story" presented in the middle of the screen, until the participant pressed the space bar.

\section{Eye-Movement Data}

First, five global measures are reported to assess the reading behavior during reading of the entire paragraphs and answering the question. Paragraph reading/ question answering time is the total time spent for reading the text, the question and the possible answers; total number of fixations is the sum of all fixations; and average fixation duration is the mean length of all fixations. Number of forward fixations refers to fixation durations following a forward (left to right) saccade. Forward saccade length is the mean length of all saccades [Rayner, 1998, 2009] (see Table 2).

Next, eight local eye-movement measures were explored in relation to the predefined target words (e.g., mouse, cat, parrot, and little; Appendix 1). First fixation duration is the duration of the initial fixation on the target word regardless of whether it is the only fixation or the first of multiple fixations, whereas single fixation duration is the duration of the initial fixation on the word when only one fixation was made on that word during first pass. Gaze duration is the sum of fixations on a word prior to moving to another word and 
Table 3. Means (and SDs) of Local Eye-Movement Data from the Target Words in Both, Inferential and Literal Conditions for ASD and Control Groups, and Overall Conditions Scores

\begin{tabular}{|c|c|c|c|c|c|c|c|}
\hline & \multirow[b]{2}{*}{$\begin{array}{c}n \\
(\mathrm{ASD} / \mathrm{TD})\end{array}$} & \multicolumn{2}{|c|}{ ASD } & \multicolumn{2}{|c|}{ Control } & \multicolumn{2}{|c|}{ Both groups } \\
\hline & & $\begin{array}{l}\text { Inferential } \\
\text { mean (SD) }\end{array}$ & $\begin{array}{c}\text { Literal } \\
\text { mean (SD) }\end{array}$ & $\begin{array}{l}\text { Inferential } \\
\text { mean (SD) }\end{array}$ & $\begin{array}{c}\text { Literal } \\
\text { mean (SD) }\end{array}$ & $\begin{array}{l}\text { Inferential } \\
\text { mean }(S D)\end{array}$ & $\begin{array}{c}\text { Literal } \\
\text { mean }(S D)\end{array}$ \\
\hline \multicolumn{8}{|c|}{ Target word } \\
\hline First fixation duration & $21 / 20$ & $224(51)$ & $210(59)$ & $213(42)$ & $210(81)$ & $218(47)$ & $210(69)$ \\
\hline Single fixation duration & $13 / 17$ & $213(53)$ & $227(68)$ & $233(52)$ & $210(41)$ & $224(52)$ & $217(54)$ \\
\hline Gaze duration & $21 / 20$ & $323(207)^{*}$ & $257(87)$ & $282(97)$ & 299 (129) & $303(162)$ & $278(110)$ \\
\hline Go-past time & $21 / 20$ & $375(208)$ & $324(126)$ & $347(144)$ & $348(209)$ & $361(178)$ & $336(170)$ \\
\hline Total fixation time & $22 / 22$ & $568(298)$ & 470 (299) & $503(237)$ & $330(188)$ & $536(268)^{* * *}$ & $450(248)$ \\
\hline Re-reading time & $15 / 13$ & $1436(2291)$ & $1121(950)$ & $883(1296)$ & $1626(3428)$ & $1179(1883)$ & 1355 (2399) \\
\hline Regression-out (\%) & $22 / 22$ & $9.12(10.29)$ & $7.10(10.90)$ & $11.18(13.56)$ & $12.96(13.51)$ & $10.15(11.94)$ & $10.47(12.39)$ \\
\hline Regression-in (\%) & $22 / 22$ & $22.05(23.90)^{*}$ & $20.29(24.28)$ & $15.99(18.40)^{*}$ & $24.12(19.96)$ & $19.02(21.30)$ & $22.20(22.05)$ \\
\hline \multicolumn{8}{|c|}{ Correct answer word/replacement word } \\
\hline First fixation duration & $21 / 21$ & $212(62)$ & $211(53)$ & $207(51)$ & $224(53)$ & $210(56)$ & $218(52)$ \\
\hline Single fixation duration & $16 / 16$ & $183(53)$ & $236(108)$ & $200(53)$ & $212(66)$ & $192(53)$ & $224(89)$ \\
\hline Gaze duration & $21 / 21$ & $253(79)$ & $276(84)$ & $265(107)$ & $279(76)$ & $259(93)$ & $277(79)$ \\
\hline Go-past time & $21 / 21$ & $304(127)$ & $343(146)$ & $350(168)$ & $343(98)$ & $327(149)$ & $343(122)$ \\
\hline Total fixation time & $22 / 22$ & $437(240)$ & $381(179)$ & $404(183)$ & $389(147)$ & $420(212)$ & $385(162)$ \\
\hline Re-reading time & $8 / 11$ & $100(78)$ & $352(463)$ & $141(120)$ & $330(386)$ & $124(104)^{*}$ & $340(408)$ \\
\hline Regression-out (\%) & $22 / 22$ & $16.73(15.76)$ & $18.96(11.63)$ & $22.78(17.23)$ & $28.03(15.44)$ & $19.75(16.60)$ & $23.49(14.26)$ \\
\hline Regression-in (\%) & $22 / 22$ & $34.89(13.94)$ & $28.86(14.88)$ & $30.28(18.73)$ & $26.75(13.79)$ & $32.79(16.45)$ & $27.80(14.22)$ \\
\hline \multicolumn{8}{|c|}{ Distractor word } \\
\hline First fixation duration & $21 / 21$ & $234(81)$ & $217(58)$ & $208(42)$ & $205(47)$ & $221(65)$ & $211(52)$ \\
\hline Single fixation duration & $14 / 17$ & $279(82)$ & $300(232)$ & $229(49)$ & $245(97)$ & $252(69)$ & $270(171)$ \\
\hline Gaze duration & $21 / 21$ & $278(92)$ & $302(119)$ & $268(86)$ & $273(91)$ & $273(88)$ & $288(105)$ \\
\hline Go-past time & $21 / 21$ & 369 (183) & $385(164)$ & $315(106)$ & $333(124)$ & $342(150)$ & $359(146)$ \\
\hline Total fixation time & $22 / 22$ & $529(333)$ & $450(242)$ & $430(201)$ & $391(153)$ & $480(276)$ & $421(202)$ \\
\hline Re-reading time & $17 / 17$ & $607(688)$ & $502(487)$ & $592(709)$ & $689(791)$ & $599(688)$ & $596(654)$ \\
\hline Regression-out (\%) & $22 / 22$ & $20.14(11.92)$ & $23.67(10.50)$ & $24.24(16.90)$ & $22.67(18.87)$ & $22.19(14.60)$ & $23.17(15.10)$ \\
\hline Regression-in (\%) & $22 / 22$ & $34.10(18.35)$ & 36.66 (15.69) & 30.07 (19.54) & $29.93(19.42)$ & $32.08(18.84)$ & 33.29 (17.78) \\
\hline
\end{tabular}

The first part illustrates the eye-movement measures from the target word (e.g., mouse), the second from the correct answer present in the text of the literal paragraphs (e.g., cat) compared to the word that replaced the correct answer in the inferential paragraphs (e.g., little), the third from the option that was present in the text as a distractor (e.g., parrot). $n=$ number of participants. First fixation duration, single fixation duration, gaze duration, go-past time, total fixation time, and re-reading time are in milliseconds.

${ }^{*} P<.05 ;{ }^{* * * P}<.001$.

go-past time is the sum of all temporally continuous fixations including fixations after a regressive eye movement to the left of the region, until the fixation point progresses to the region to the right. Total fixation time is the sum of all fixations on the target word. Rereading time is the total fixation durations in a region after having left that region to the right. Finally, regressions-out refers to the probability of making a leftward eye movement out of the target word before leaving the word to the right, whereas regressions-in refers to the probability of making a leftward eye movement into the target word having already left that word to the right [Rayner, 1998, 2009]. For all local measures, with the exception of regression probabilities, values of zero were excluded. Participants who had zero reading times in all items in one or both conditions were excluded from the analyses for the given six eye-movement measures. Consequently, the number of participants kept for each analysis varied between the eye-movement variables (see Table 3).

\section{Statistical Analyses}

All global eye-movement data and all log-transformed local eye-movement data, except for regressions, were analyzed using mixed (group $\mathrm{x}$ condition) ANOVAs across subjects $\left(F_{1}\right)$ and items $\left(F_{2}\right)$. Bonferroni correction was applied in order to allow multiple comparisons. Nonparametric analyses across subjects and items were performed on accuracy in answering the question and the proportion of regressions made out of and into the target word. Main effects of condition and group were assessed using Wilcoxon Signed-Rank Test $\left(z_{1}, z_{2}\right.$, across items and conditions, respectively), or Mann-Whitney $U$-Test $\left(U_{1}, U_{2}\right)$, respectively. The condition by group interaction was probed using Wilcoxon Signed-Rank Test separately for each group and Mann-Whitney $U$ Tests separated for condition. The effect sizes were interpreted in terms of Fritz, Morris, and Richler [2012] guidelines, with values of $.10, .24$, and .37 representing small, medium, and large effect sizes, respectively. 


\section{Results}

Accuracy

In the whole sample, significantly lower accuracy was observed in the inferential than in the literal condition, $Z_{1}=-4.02, \quad P<.001, \quad r=.43 ; \quad Z_{2}=-3.03, \quad P=.002, \quad r=$ .39. No main effect of group or interaction was observed (see Table 2).

\section{Eye-Movement Data Recording and Outlier Exclusion}

The velocity threshold was set to 30 degrees/sec and the acceleration threshold to 8000 degrees $/ \mathrm{sec}^{2}$ to detect saccades of 0.5 degrees of visual angle or greater. Any sample that was not in a saccade was considered to be in a fixation. Fixations less than $80 \mathrm{~ms}$ and longer than $800 \mathrm{~ms}$ were excluded from the dataset. Data from each paragraph were visually inspected and those containing excessive blinks or track losses were excluded from the final analyses, resulting in data loss of $1.8 \%$ and $0.2 \%$ for ASD and control groups, respectively. Outliers for each eye-movement measure (>2.5 SDs below or above the subject mean for each condition) were excluded from the analyses. This resulted in the exclusion of a total of $23.3 \%$ of the data across all analyses and did not differ across groups or conditions.

\section{Eye-Movement Measures}

Global Eye-Movement Analyses

The inference condition showed a longer paragraph reading/question answering time, $F_{1}(1,42)=32.53$, $P<.001, \eta^{2}=.44 ; F_{2}(1,29)=33.25, P<.001, \eta^{2}=1$, and a greater total number of fixations, $F_{1}(1,42)=36.62$, $P<.001, \eta^{2}=.47 ; F_{2}(1,29)=37.11, P<.001, \eta^{2}=1$. No main effect of condition (all Ps $>.19$ ), group (all Ps $>$.46), or interaction (all Ps $>.36$ ) between group and condition were found for the average of fixation duration, number of forward fixations, and forward saccade length (see Table 2).

\section{Local Eye-Movement Analyses}

First, eye-movement measures on the target word (e.g., mouse) that allowed the participants to infer the correct answer were explored. The reading behavior on the target word when it was in the inferential paragraphs was compared with the reading behavior on the target word when it was in the literal paragraphs. The aim was to observe if the reading behavior in relation to the target word changed between the literal condition, where the correct answer was already available in the text, and consequently the target word was an additional, but not necessary cue, and the inferential condition, where the only cue to answer to the question was the target word. A significant interaction of group and condition was found in gaze durations on the target word, $F_{1}$

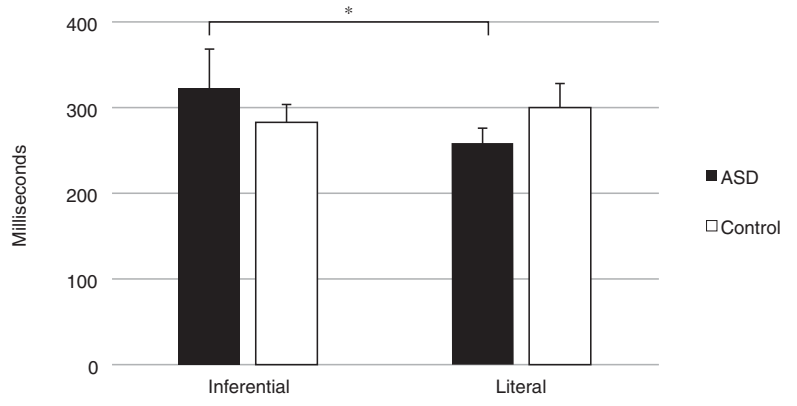

Figure 1. Mean gaze duration on the target word in both, inferential and literal conditions for ASD and control groups. Error bars indicate standard errors. ${ }^{*} P<.05$.

$(1,39)=5.22, P=.03, \eta^{2}=.12 ; F_{2}(1,29)=8.85, P=.01$, $\eta^{2}=.82$. Post hoc analyses showed that the ASD group, but not the control group, displayed significantly longer $(P=.02)$ gaze durations on the target words in the inferential than literal condition (Fig. 1).

Furthermore, the ASD group made overall more regressions-in to the target word, $U_{1}=149, Z=-2.18$, $P=.03, r=.33, U_{2}=201, \quad Z=-3.68, P<.001, r=.56$, compared to the control group. The inference condition showed longer total fixation times, $F_{1}(1,42)=14.84$, $P<.001, \eta^{2}=.26 ; F_{2}(1,29)=20.12, P<.001, \eta^{2}=.99$. No main effects of condition (all Ps $>.18$ ), group (all Ps $>.67$ ), or interaction (all Ps $>.24$ ) between condition and group were found in any of the early measures of processing: first fixation duration, single fixation duration, and gaze duration. No main effect of condition (all Ps $>.11$ ), group (all Ps $>.37$ ), or interaction (all Ps $>$.37) between condition and group was observed in any other eye-movement measures (Table 3 shows mean reading times/probabilities and SDs in parentheses). Apart from regressions-in, it was not possible to conduct analyses from the target separately for the instances in which the word was visited from the text vs. when the word was visited from the question, due to the paucity of the extracted data.

The analyses above showed that readers in the ASD group made more regressions into the target word. We, therefore, proceeded to analyze in greater detail the possible origin of these regressions. The percentage of total number of regressions made into the target word from within the remaining part of the text after the target word (from the 56th word to the 60th word) and the percentage of regressions made into the target word from within the question were compared. Overall, the target word was visited significantly more from the text $(M=31.52, \quad S D=16.07)$, than from the question $(M=10.64, \quad \mathrm{SD}=8.89), \quad z_{1}=-5.38, \quad p<.001, \quad r=.81$, $Z_{2}=-4.78, P<.001, r=.62$. The target word was also visited from the text more in the inferential condition $(M=37.08, \quad S D=19.39)$ than the literal condition $(M=25.94, \quad \mathrm{SD}=19.65), \quad z_{1}=-3.51, \quad P<.001, \quad r=.53$, 


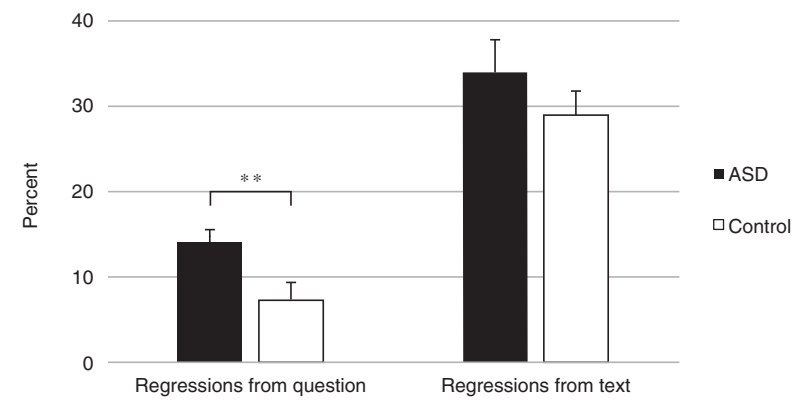

Figure 2. Percentage of total number of regressions-in to the target word from within the question and the text, for ASD and control groups. Error bars indicate standard errors. ${ }^{*} P<.01$.

$z_{2}=-2.76, p=.01, r=.36$. This was not the case for regressions into the target word from within the question $(P=.52)$. There was an interaction of origin of the regressions by group (see Fig. 2). Overall, the ASD group made significantly more regressions into the target word from within the question $(M=13.99, \mathrm{SD}=7.56), U_{1}=118.0$, $Z=-2.93, P=.003, r=.44, U_{2}=221, Z=-3.41, P=.001$, $r=.51$, compared to the control group $(M=7.28$, $\mathrm{SD}=9.91)$. This was the case in both the inferential $(M=15.34, \mathrm{SD}=11.06), U_{1}=118.0, Z=-2.98, P=.003$, $r=.45, U_{2}=247, z=-3.05, P=.002, r=.39$, and the literal conditions $(M=12.82, \mathrm{SD}=10.28), U_{1}=149.5, z=-2.25$, $P=.02, r=.34, U_{2}=328, Z=-1.88, P=.06, r=.24$ (inferential: $M=7.88, \mathrm{SD}=13.43$, literal: $M=6.67, \mathrm{SD}=8.97$, for the control group). No significant difference $(P=.33)$ was found between groups (ASD group: $M=34.02$, $\mathrm{SD}=18.42$, control group: $M=29.03, \mathrm{SD}=13.27$ ) for the regressions into the target word form within the text.

Second, the local eye-movement data from the word that contained the correct answer present in the text of the literal condition paragraphs (correct answer word, e.g., cat; Appendix 1) were compared to the word that replaced it in the inferential paragraphs (replacement word, e.g., little; Appendix 1). The replacement word, present in the inferential paragraph, was considered a control for the correct-answer word, present in the text in the literal paragraphs. The replacement word showed longer re-reading times, $F_{1}(1,17)=10.17, P=.01$, $\eta^{2}=.37 ; F_{2}(1,23)=7.04, P=.01, \eta^{2}=.23$, compared to the correct answer word, but all other effects were nonsignificant. No main effect of condition (all Ps $>.07$ ), group (all Ps $>.74$ ), or interaction (all Ps $>.27$ ) were found for any of the other eye-movement variables (see Table 3 ).

Third, the local eye-movement data from the target word (e.g., mouse; Appendix 1) were compared with the replacement word (e.g., little; Appendix 1) only within the inferential paragraphs. A main effect of condition was found for gaze duration, but all other effects were nonsignificant. The target word received longer gaze durations, $F_{1}(1,39)=5.45, P=.03, \eta^{2}=.12 ; F_{2}(1,29)=5.17, P=.03$, $\eta^{2}=.15$, compared to the replacement word. Go-past time showed a significant interaction effect between condition and group, $F_{1}(1,39)=5.82, P=.02, \eta^{2}=.13, F_{2}(1,29)=$ 3.53, $P=.09, \eta^{2}=.05$. No main effects were significant. Post hoc analyses showed a significant difference $(P=.01)$ between conditions in the ASD group; proportions of gopast time on the target word were higher compared to gopast time on the replacement word for the ASD group, and not for the control group. However, $F_{2}$ analyses showed no significant interaction in go-past time. Therefore, the results concerning the interaction effect on go-past time remain inconclusive. A main effect of condition was observed for the proportion of regressions made out of, and into the target and replacement words. More regressions-out of the replacement word were observed compared to the target word, $z_{1}=-3.08, P=.002, r=.46$, $z_{2}=-3.53, P<.001, r=.46$, for both contrasts. More regressions-in to the replacement word were observed compared to the target word, $z_{1}=-4.10, P<.001, r=.62$, $Z_{2}=-2.52, P=.01, r=.33$. No main effect of condition (all Ps $>.10$ ), group (all Ps>.16), or interaction (all $P s>.09)$ between condition and group were found for any of the other eye-movement variables (see Table 3).

Fourth, the reading behavior on the correct answer word (e.g., cat; Appendix 1) was compared with the target word (e.g., mouse; Appendix 1), only within the literal paragraphs. A main effect of condition was found for regression-out, $Z_{1}=-4.51, \quad P<.001, \quad r=.68$, $z_{2}=-2.79, P=.01, r=.36$. More regressions-out from the correct answer word was observed compared to the target word. No main effect of condition (all Ps $>.06$ ), group (all Ps $>.16$ ), or interaction (all Ps $>.43$ ) between condition and group were found for any of the other eye-movement variables (see Table 3 ).

Finally, the analyses of the option that was present in the text as a distractor (distractor word, e.g., parrot; Appendix 1) showed a significant interaction between condition and group in the regressions-out from the distractor, $F_{1}(1,42)=4.53, P=.04, \eta^{2}=.09$. Post hoc analyses showed a marginal difference $(P=.08)$ between groups in the literal condition and indicated a close to significant difference $(P=.08)$ between conditions for the control group; proportions of regressions-out from the distractor were higher in the literal condition compared to the inferential condition for the ASD group, and the control group showed the opposite behavior. $F_{2}$ analyses showed no interaction $(P=.48)$ between condition and group in the regressions out of the distractor. Therefore, the results concerning regressions-out from the distractor word are considered inconclusive. A main effect of inference condition was observed in the proportion of regressions into the word, $F_{1}(1,16)=4.42, P=.04, \eta^{2}=.09$, with more regressions-in for the literal paragraphs compared to the inferential paragraphs. Again, $F_{2}$ analyses showed no significant main effect of condition $(P=.56)$ in the proportion of regressions into the distractor. Therefore, the 
results concerning the regressions into the distractor word are considered inconclusive. No main effect of inference condition (all Ps $>.33$ ), group (all Ps $>.19$ ), or interaction (all Ps $>.27$ ), between condition and group in any of these eye-movement measures were observed (see Table 3 ).

\section{Discussion}

This study aimed to explore inference generation skills and reading strategies in a group of children and adolescents with ASD compared to a closely-matched group of control peers. The first aim was to determine performance when responding to literal and inferential comprehension questions. Results showed that participants with ASD were as accurate as the control group in responding to both questions present in the paragraph assigned to the literal and inferential condition. The result that accuracy in the inferencing task was comparable across ASD and control participants is in agreement with some [LaPointe-Speer, 2007; Saldaña \& Frith, 2007; Sansosti et al., 2013], but not all previous studies [Jolliffe \& Baron-Cohen, 1999b, 2000; Loukusa et al., 2007; Norbury \& Bishop, 2002]. The lack of differences in our study is perhaps not surprising, given that the current group of participants was composed of individuals with ASD, all comparable to the control group, both with respect to language skills and overall reading comprehension. Studies reporting differences in inferencing skill between ASD and TD have often included participants with poorer language abilities [Norbury \& Bishop, 2002]. These results support the idea that a great proportion of poorer performance of readers with autism is the result of their lower level of language abilities [Lucas \& Norbury, 2014; Ricketts et al., 2013].

Alternatively, this lack of differences could be explained by the limited emotional [Bodner et al., 2015] and social [White et al., 2009] content of our stories. Bodner et al. [2015] found that when emotional content was the object of the inference, individuals with ASD performed worse than TD controls. Also, our text and questions were presented simultaneously on a single screen. Oakhill [1984] reported that, in skilled comprehenders, there is a facilitation effect provided by the presence of the text during question-answering. In our study, it is possible that the presence of the text on the same screen as the question and possible answers brought the accuracy performance of the ASD group to control standard. We had specifically aimed at reducing the working memory demands, as our research focus was on reading comprehension differences between control and ASD groups, and not on the role of working memory during the task. In any case, the results on accuracy do suggest that ASD individuals with good oral language skills are able to respond to simple global coherence inferences.
The current study also examined reading behavior during inferencing and question answering by monitoring readers' eye movements. Results showed a similar reading pattern between the groups in global reading of the entire paragraph. However, fine-grained analyses on the target words showed that the two groups exhibited subtly different reading patterns that seem indicative of greater effort in producing the inferences. Gaze durations on the target word were longer for participants with autism in the inferential condition, but not in the literal condition. The control participants apparently had no similar difficulty, judging by their similar gaze durations in both conditions. The longer gaze duration may be due to the fact that when the participants with autism encountered the target word, it was less expected in that context [Rayner \& Well, 1996].

It should be noted, though, that individuals with ASD had comparable first and single fixation durations to the control participants indicating that the early processing of the target word and lexical access are intact [Rayner \& Pollatsek, 1987]. These results are consistent with the lack of differences in the early measures in the noninferential sentence-processing tasks presented by Howard et al. [2016]. The lack of differences between groups in both reading behavior for the entire paragraph and the early processing of the target word, could be indicative of similar ability in the ASD group in constructing the text based comprehension or propositional representation [Kintsch \& Rawson, 2005; Van Dijk \& Kintsch, 1983]. In the present study, our ASD group appeared to have no difficulty processing the meaning of the text as such, prior to integrating background knowledge and generating inferences to build the situation model.

Our data are in line with the study by Sansosti et al. [2013] which showed similar accuracy in responding to questions for ASD and control groups - replicating also the Saldaña and Frith, [2007] results. Similar findings in accuracy, albeit with materials tapping different kinds of inferences, were observed in the current study and the study by Sansosti et al. We explored global spontaneous elaborative inferences in short passages. These are inferences that develop and enrich the interpretation of a text by filling in details such as the framework of a typical situation or the causes of a character's actions [McKoon \& Ratcliff, 1992]. On the other hand, Sansosti et al. explored local bridging inferences using short sentences. These are inferences that are essential for comprehension and provide connections between the different propositions underlying the discourse [Haviland \& Clark, 1974]. Still, in line with our results, Sansosti et al. [2013] demonstrate that the ASD group spent more time fixating the text, made more fixations overall, and made more regressions while reading short sentences that needed psychological or social bridging inferences and knowledge interpretation for comprehension, compared to a control group. Howard et al. 
[2016] did not find any differences in first pass or global reading measures, but their tasks are less comparable, as they did not require the production of inferences.

In addition to spending more time processing the target word, individuals with ASD made more regressions into the target word compared to control readers. A larger number of regressions is consistent with both Sansosti et al. [2013] and Howard et al.'s [2016] results. In our case, due to having the text and question present simultaneously on screen, we could analyze where these regressions to the target word were coming from. Further analyses showed that for both groups more regressions into the target word from within the remaining part of the text (after the target word) were made compared to the regressions made into the target word coming from the question. However, when only the regressions from the question were explored, the ASD group showed more regressions compared to the control group for both the inferential and the literal condition. Hence, it is possible that ASD participants had a greater needed to re-inspect the target word in order to answer the question, whether an inference was necessary or not. ASD participants may find initial attempts to construct a situation model unsuccessful, thus requiring subsequent regressions into the relevant word to re-check and re-process pieces of information highlighted by the question [Blanchard \& Iran-Nejad, 1987; Ehrlich, 1983; Just \& Carpenter, 1978; Shebilske \& Fisher, 1983; Vauras, Hyönä, \& Niemi, 1992]. The lack of differences between groups in both reading behavior for the entire paragraph and the early processing of the target word may suggest that the early cursory processing, defined as text-based comprehension or propositional representation of text in our ASD sample is similar to typical readers. However, in our ASD group, difficulties emerged during the situation model or mental model representation [Kintsch \& Rawson, 2005; Van Dijk \& Kintsch, 1983]. Individuals with autism may have an underspecified situation model [Tirado \& Saldaña, 2015], that lacks sufficient detail to respond to the question even when the response is actually presented in the text. Another explanation comes from previous studies that have shown that re-reading reflects attempts to re-engage working memory of prior text segments which are important to readers' reading goals [Kaakinen \& Hyönä, 2005, 2008; Kaakinen, Hyönä, \& Keenan, 2003]. Similar behavior is seen in poor readers, dyslexic readers, and beginner readers [Adler-Grinberg \& Stark, 1978; Blythe \& Joseph, 2011; Eden, Stein, Wood, \& Wood, 1994; Elterman, Abel, Daroff, Dell'osso, \& Bornstein, 1980; Lefton, Nagle, Johnson, \& Fisher, 1979; Martos \& Vila, 1990]. Hence, more regressions back toward the target word may reflect a backtracking technique of reading or ineffective use of text, as Murray and Kennedy [1988] found in poor readers. An alternative, although not totally incompatible, explanation is provided by Howard et al. [2016]. They attributed increased second pass reading in their participants to a more cautious reading strategy. In our particular task, this approach could actually be justified if they were finding subtle difficulties in some of the texts. Readers with autism could have more difficulties in constructing the situation model and also be extra-cautious when responding to questions about a text.

\section{Conclusion, Limitations, and Future Prospects}

In conclusion, results from the current study support the idea that readers with ASD may have a less specified situation model than their control peers even when they have relatively high levels of receptive language, nonverbal IQ, reading speed and comprehension skill. Despite registering as many correct responses to comprehension questions as the control group, the ASD group had longer gaze durations while reading texts that required inferencing. It appears that readers with ASD had to work harder during the reading process to reach the level of comprehension of the control participants. In addition, they seemed less sure about how to respond to questions about the text, even when the answer was explicitly presented. Although the present study yielded some novel and relevant findings, they need to be interpreted in the light of some limitations. First, the standardized tests used to assess language and reading skills in the present study may not have been sensitive to differences between the two groups in other important cognitive functions involved in reading. For example, higher cognitive and linguistic components such as executive control could play a relevant role in shaping the differences in reading behavior between groups. In addition, higher-level linguistic components such as passage-level listening comprehension and story recall were not assessed in the present sample. These linguistic comprehension challenges could impact on the creation of a coherent situation model and possibly explain why individuals with ASD appeared to work harder to reach the level of comprehension of the control group. Future studies should aim to explore broadly the cognitive and linguistic profiles of participants in order to examine the possible influence of these variables on reading behavior. Also, due to the amount of time required to complete testing in each session, we recruited a relatively small sample. We urge researchers to replicate the present findings in other samples. Future studies should also seek to replicate these results using different materials, e.g., texts with social context or emotional content, and in different samples of ASD individuals with varying skills levels.

\section{Acknowledgments}

This research has received funding from the European Union's Seventh Framework Program for research, 
technological development and demonstration under grant agreement $n^{\circ}$ 316748. The authors thank the participants, the families, Sam Hutton from SR Research, Sobh Chahboun and the Asociación Malagueña Síndrome de Asperger.

\section{Conflict of Interest}

The authors declare that they have no conflict of interest.

\section{Appendix 1. Paragraph in Both Conditions, Inferential and Literal}

\begin{tabular}{|c|c|}
\hline $\begin{array}{l}\text { Inferential } \\
\text { condition } \\
\text { paragraph }\end{array}$ & $\begin{array}{l}\text { It was Monday morning and was really sunny. } \\
\text { Mr Francisco fed his parrot and then went } \\
\text { over to check that little Mico was ok. He was } \\
\text { in a deep sleep and appeared to be dreaming. } \\
\text { Mico's legs were moving back and forth as } \\
\text { if he was imagining chasing a mouse very fast, } \\
\text { trying to catch it. } \\
\text { Era lunes por la mañana y hacia mucho sol. } \\
\text { Don Francisco le dio la comida a su loro y luego } \\
\text { se fue para ver si el pequeño Mico estaba bien. } \\
\text { Dormía profundamente y parecía que estaba } \\
\text { soñando. Las piernas de Mico se movían para } \\
\text { adelante y para atrás como si estuviera } \\
\text { imaginando a un ratón que perseguía } \\
\text { velozmente, intentando atraparlo. }\end{array}$ \\
\hline $\begin{array}{l}\text { Literal condition } \\
\text { paragraph }\end{array}$ & $\begin{array}{l}\text { It was Monday morning and was really sunny. } \\
\text { Mr Francisco fed his parrot and then went } \\
\text { over to check that the cat Mico was ok. } \\
\text { He was in a deep sleep and appeared to } \\
\text { be dreaming. Mico's legs were moving } \\
\text { back and forth as if he was imagining } \\
\text { chasing a mouse very fast, trying to catch it. } \\
\text { Era lunes por la mañana y hacia mucho sol. } \\
\text { Don Francisco le dio la comida a su loro y luego } \\
\text { se fue para ver si el gato Mico estaba bien. } \\
\text { Dormía profundamente y parecía que estaba } \\
\text { soñando. Las piernas de Mico se movían para } \\
\text { adelante y para atrás como si estuviera } \\
\text { imaginando a un ratón que perseguía } \\
\text { velozmente, intentando atraparlo. }\end{array}$ \\
\hline Question & $\begin{array}{l}\text { What animal is Mico? } \\
\text { ¿Qué animal es Mico? }\end{array}$ \\
\hline Correct answer & $\begin{array}{l}\text { a. A cat } \\
\text { a. Un gato }\end{array}$ \\
\hline In text distractor & $\begin{array}{l}\text { b. A parrot } \\
\text { b. Un loro }\end{array}$ \\
\hline Semantic distractor & $\begin{array}{l}\text { c. A dog } \\
\text { c. Un perro }\end{array}$ \\
\hline
\end{tabular}

One paragraph example, first of a story composed of five paragraphs. The first paragraph example pertains at the inferential condition, and the second at the literal condition. Underlined is the target word that allowed the participant to answer to the question and in italics one of the option contained in the text. Bolded is the correct answer contained in the text, only for the literal condition. Wavy underlined is the word that substituted the correct answer only in the inferential paragraph. The dashed option corresponds to the semantic distractor. The original test in Spanish is presented under the English translation for all the trial components.

\section{References}

Adler-Grinberg, D., \& Stark, L. (1978). Eye movement, scanpaths and dyslexia. American Journal of Optometry and Psychological Optics, 55, 557-570.

Bishop, D.V.M. (1983). Test for reception of grammar: TROG. England: Medical Research Council, Chapel Press.

Blanchard, H.E., \& Iran-Nejad, A. (1987). Comprehension process and eye movement patterns in the reading of surpriseending stories. Discourse Processes, 10, 127-138. doi: $10.1080 / 01638538709544663$

Blythe, H.I., \& Joseph, H.S.S.L. (2011). Children's eye movements during reading. In S.P. Liversedge, I. Gilchrist, \& S. Everling, (Eds.), The Oxford Handbook of Eye Movements (pp. 643-662). Oxford: Oxford University Press.

Bodner, K.E., Engelhardt, C.R., Minshew, N.J., \& Williams, D.L. (2015). Making inferences: Comprehension of physical causality, intentionality, and emotions in discourse by highfunctioning older children, adolescents, and adults with autism. Journal of Autism and Developmental Disorders, 45, 2721-2733. doi:10.1007/s10803-015 2436-3

Cain, K., \& Bignell, S. (2014). Reading and listening comprehension and their relation to inattention and hyperactivity. British Journal of Educational Psychology, 84, 108-124. doi: 10.1111/bjep.12009

Cain, K., Oakhill, J.V., Barnes, M.A., \& Bryant, P.E. (2001). Comprehension skills, inference making ability, and their relation to knowledge. Memory \& Cognition, 29, 850-859. doi:10.3758/BF03196414

Cook, A.E., \& Myers, J.L. (2004). Processing discourse roles in scripted narratives: The influences of context and world knowledge. Journal of Memory and Language, 50, 268-288. doi:10.1016/j.jml.2003.11.003

Dunn, L.M., Dunn, L.M., \& Arribas, D. (2006). PPVT-III peabody: Test de vocabulario en imágenes. Madrid: TEA.

Eberhardt, M., \& Nadig, A. (2016). Reduced sensitivity to context in language comprehension: A characteristic of autism spectrum disorders or of poor structural language ability? Research in Developmental Disabilities. doi:10.1016/ j.ridd.2016.01.017.

Eden, G.F., Stein, J.F., Wood, H.M., \& Wood, F.B. (1994). Differences in eye movement and reading problems in dyslexic and normal children. Vision Research, 34, 1354-1358. doi: 10.1016/0042-6989(94)90209-7

Ehrlich, K. (1983). Eye movements in pronoun assignment: A study of sentence integration. In K. Rayner (Ed.), Eye Movements in Reading: Perceptual and Language Processes (pp. 253-268). New York: Academic Press.

Elterman, R.D., Abel, L.A., Daroff, R.B., Dell'osso, L.F., \& Bornstein, J.L. (1980). Eye movement patterns in dyslexic children. Journal of Learning Disabilities, 13, 312-317.

Frith, U., \& Snowling, M. (1983). Reading for meaning and reading for sound in autistic and dyslexic children. British Journal of Developmental Psychology, 1, 329-342. doi: 10.1111/j.2044-835X.1983.tb00906.x.

Fritz, C.O., Morris, P.E., \& Richler, J.J. (2012). Effect size estimates: Current use, calculations, and interpretation. Journal of Experimental Psychology: General, 141, 2-18. doi: $10.1037 / \mathrm{a} 0024338$ 
Garrod, S., \& Terras, M. (2000). The contribution of lexical and situational knowledge to resolving discourse roles: Bonding and resolution. Journal of Memory and Language, 42, 526544. doi:10.1006/jmla.1999.2694

Happé, F. (1997). Central coherence and theory of mind in autism: Reading homographs in context. British Journal of Developmental Psychology, 15, 1-2. doi:10.1111/j.2044835X.1997.tb00721.x.

Haviland, S.E., \& Clark, H.H. (1974). What's new? Acquiring information as a process in comprehension. Journal of Verbal Learning and Verbal Behavior, 13, 512-521. doi: 10.1016/S0022-5371(74)80003-4

Howard, P.L., Liversedge, S.P., \& Benson, V. (2016). Benchmark eye movement effects during natural reading in autism spectrum disorder. Journal of Experimental Psychology Learning, Memory, and Cognition. doi:10.1037/ $\mathrm{x} \operatorname{lm} 0000289$

Jolliffe, T., \& Baron-Cohen, S. (1999a). The Strange Stories test: A replication with high-functioning adults with autism or Asperger syndrome. Journal of Autism and Developmental Disorders, 29, 395-406. doi:10.1023/A:1023082928366

Jolliffe, T., \& Baron-Cohen, S. (1999b). A test of central coherence theory: Linguistic processing in high-functioning adults with autism or Asperger syndrome: Is local coherence impaired? Cognition, 71, 149-185. doi:10.1016/S00100277(99)00022-0

Jolliffe, T., \& Baron-Cohen, S. (2000). Linguistic processing in high-functioning adults with autism or Asperger's syndrome. Is global coherence impaired? Psychological Medicine, 30, 1169-1187. doi:10.1017/S003329179900241X

Juhasz, B.J., \& Pollatsek, A. (2011). Lexical influences on eye movements in reading. In S. Liversedge, I. Gilchrist, \& S. Everling (Eds.), The Oxford Handbook of Eye Movements (p. 874). Oxford: Oxford University Press.

Just, M.A., \& Carpenter, P.A. (1978). Inference processing during reading: Reflections form eye fixations. In J.W. Senders, D.F. Fisher, \& R.A. Monry (Eds.), Eye Movements and the Higher Psychological Functions (pp. 157-174). Hillsdale: Erlabaum.

Kaakinen, J.K., \& Hyönä, J. (2005). Perspective effects on expository text comprehension: Evidence from think-aloud protocols, eyetracking and recall. Discourse Processes, 40, 239-257.

Kaakinen, J.K., \& Hyönä, J. (2008). Perspective-driven text comprehension. Applied Cognitive Psychology, 22, 319334. doi:10.1002/acp.1412

Kaakinen, J.K., Hyönä, J., \& Keenan, J. (2003). How prior knowledge, working memory capacity, and relevance of information effect eye-fixations in expository text. Journal of Experimental Psychology Learning, Memory, and Cognition, 29, 447-457. doi:10.1037/0278-7393.29.3.447

Kintsch, W., \& Rawson, K.A. (2005). Comprehension. In M.J. Snowling \& C. Hulme (Eds.), The Science of Reading. A Handbook (pp. 209-226). Oxford: Blackwell Publishing.

Kintsch, W., \& Van Dijk, T.A. (1978). Toward a model of text comprehension and production. Psychological Review, 85, 363-394.

Kirk, S.A., McCarthy, J.J., \& Kirk, W.D. (1968). Illinois test of psycholinguistic abilities. Urbana: University of Illinois Press.
LaPointe-Speer, L. (2007). Text comprehension as an implicit measure of cognitive functioning in individuals with autism. Dissertation Abstract International, 68, 103B. (UMI No. 3270270). Retrieved August 10, 2011 from ProQuest Dissertations \& Theses (PQDT) database. pqdtopen.proquest.com/ search.html

Lefton, L.A., Nagle, R.J., Johnson, G., \& Fisher, D.F. (1979). Eye movement dynamics of good and poor readers: Then and now. Journal of Reading Behavior, 11, 319-328. doi: 10.1080/10862967909547338

Lord, C., Risi, S., Lambrecht, L., Cook, E.H.J., Leventhal, B.L., DiLavore, P.C., ... Rutter, M. (2000). The autism diagnostic schedule-generic: A standard measures of social and communication deficits associated with the spectrum of autism. Journal of Autism and Developmental Disorders, 30, 205-223.

Loukusa, S., Leinonen, E., Kuusikko, S., Jussila, K., Matila, M.L., Ryder, N., ... Moilanen, I. (2007). Use of the context in pragmatic language comprehension by children with Asperger syndrome or high-functioning autism. Journal of Autism and Developmental Disorders, 37, 1049-1059. doi: $10.1007 / \mathrm{s} 10803-006-0247-2$

Lucas, R., \& Norbury, C.F. (2014). Levels of text comprehension in children with autism spectrum disorders (ASD): The influence of language phenotype. Journal of Autism and Developmental Disorders, 44, 2756-2768. doi:10.1007/ s10803-014-2133-7

Lucas, R., \& Norbury, C.F. (2015). Making inferences from text: It's vocabulary that matters. Journal of Speech, Language, and Hearing Research, 58, 1224-1232. doi:10.1044/ 2015_JSLHR-L-14-0330

Martos, F.J., \& Vila, J. (1990). Differences in eye movement control among dyslexic, retarder and normal readers in the Spanish population. Reading and Writing, 2, 175-188. doi: 10.1007/BF00401801

Mayes, S.D., \& Calhoun, S.L. (2003). Analysis of WISC-III, Standford-Binet: IV, and academic achievement test scores in children with autism. Journal of Autism and Developmental Disorders, 33, 329-341. doi:10.1023/A:1024462719081

Mayes, S.D., \& Calhoun, S.L. (2008). WISC-IV and WIAT-II profiles in children with high-functioning autism. Journal of Autism and Developmental Disorders, 38, 428-439. doi: 10.1007/s10803-007-0410-4

McKoon, G., \& Ratcliff, R. (1992). Inference during reading. Psychological Review, 99, 440-466.

Mendoza, E., Carballo, G., Muñoz, J., \& Fresneda, M.D. (2005). CEG, test de comprensión de estructuras gramaticales. Madrid: TEA

Miller, A.C., Keenan, J.M., Betjemann, R.S., Willcutt, E.G., Pennington, B.F., \& Olson, R.K. (2013). Reading comprehension in children with ADHD: Cognitive underpinnings of the centrality deficit. Journal of Abnormal Child Psychology, 41, 473-483. doi:10.1007/s10802-012-9686-8

Minshew, N.J., Goldstein, G., \& Siegel, D.J. (1995). Speech and language in high-functioning autistic individuals. Neuropsychology, 9, 255-261. doi:10.1037/0894-4105.9.2.255

Murray, W.S., \& Kennedy, A. (1988). Spatial coding in the processing of anaphor by good and poor readers: Evidence from eye movement analyses. The Quarterly Journal of Experimental Psychology, 40, 693-718. doi:10.1080/ 14640748808402294 
Nation, K., Clarke, P., Wright, B., \& Williams, C. (2006). Patterns of reading ability in children with autism spectrum disorder. Journal of Autism and Developmental Disorders, 36, 911-919. doi:10.1007/s10803-006-0130-1

Norbury, C.F., \& Bishop, D.V.M. (2002). Inferential processing and story recall in children with communication problems: A comparison of specific language impairment, pragmatic language impairment and high-functioning autism. International Journal of Communication Disorders, 37, 227-251. doi:10.1080/13682820210136269

Norbury, C.F., \& Nation, K. (2011). Understanding variability in reading comprehension in adolescents with autism spectrum disorders: Interactions with language status and decoding skills. Scientific Studies of Reading, 15, 191-210. doi:10.1080/10888431003623553

Oakhill, J. (1984). Inferential and memory skills in children's comprehension of stories. British Journal of Educational Psychology, 54, 31-39. doi:10.1111/j.2044-8279.1984.tb00842x

O’Brien, E.J., Shank, D.M., Myers, J.L., \& Rayner, K. (1988). Elaborative inferences during reading: Do they occur online? Journal of Experimental Psychology: Learning, Memory, and Cognition, 14, 410-420. doi:10.1037/02787393.14.3.410.

Rayner, K. (1998). Eye movements in reading and information processing: 20 years of research. Psychological Bulletin, 124, 372-422. doi:10.1037/0033-2909.124.3.372

Rayner, K. (2009). Eye movements and attention in reading, scene perception, and visual search. The Quarterly Journal of Experimental Psychology, 62, 1457-1506. doi:10.1080/ 17470210902816461

Rayner, K., \& Pollatsek, A. (1987). Eye movements in reading: A tutorial review. In M. Coltheart (Ed.), Attention and Performance (pp. 327-362). London: Erlbaum.

Rayner, K., \& Well, A.D. (1996). Effects of contextual constraint on eye movements in reading: A further examination. Psychonomic Bulletin \& Review, 3, 504-509. doi: 10.3758/BF03214555

Real Academia Española: Banco de datos (CORDE) [en línea]. Corpus diacrónico del español. <http://www.rae.es $>$ [09/ 01/15]

Ricketts, J. (2011). Research review: Reading comprehension in developmental disorders of language and communication. Journal of Child Psychology and Psychiatry, 52, 1111-1123. doi:10.1111/j.1469-7610.2011.02438.x

Ricketts, J., Jones, C.R.G., Happé, F., \& Charman, T. (2013). Reading comprehension in autism spectrum disorders: The role of oral language and social functioning. Journal of Autism and Developmental Disorders, 43, 807-816. doi: 10.1007/s10803-012-1619-4
Saldaña, D., \& Frith, U. (2007). Do readers with autism make bridging inferences from world knowledge? Journal of Experimental Child Psychology, 96, 310-319. doi:10.1016/ j.jecp.2006.11.002

Sansosti, F.J., Was, C., Rawson, K.A., \& Remaklus, B.L. (2013). Eye movements during processing of text requiring bringing inferences in adolescents with higher functioning autism spectrum disorders: A preliminary investigation. Research in Autism Spectrum Disorders, 7, 1535-1542. doi: 10.1016/j.rasd.2013.09.001

Shebilske, W.L., \& Fisher, D.F. (1983). Eye movements and context effects during reading of extended discourse. In $\mathrm{K}$. Rayner (Ed.), Eye Movements in Reading: Perceptual and Language Processes (pp. 153-179). New York: Academic Press.

Snyder, L., \& Caccamise, D. (2010). Comprehension processes for expository text: Building meaning and making sense. In M. Nippold \& C.M. Scott (Eds.), Expository Discourse in Children, Adolescents, and Adults (pp. 13-39). New York, NY: Psychology Press.

Tirado, M.J., \& Saldaña, D. (2015). Readers with autism can produce inferences, but they cannot answer inferential questions. Journal of Autism and Developmental Disorders, 46, 13-11. doi:10.1007/s10803-015-2648-6

Toro, J., Cervera, M., \& Urío, C. (2002). Escala magallanes de lectura y escritura. TALE-2000 (EMLE). Madrid: Grupo ALBOR-COHS.

Van Dijk, T.A., \& Kintsch, W. (1983). Strategies of discourse comprehension. New York: Academic Press.

Vasishth, S., von der Malsburg, T., \& Engelmann, F. (2012). What eye movement can tell us about sentence comprehension. Wiley Interdisciplinary Reviews: Cognitive Science, 4, 125-134. doi:10.1002/wcs.1209

Vauras, M., Hyönä, J., \& Niemi, P. (1992). Comprehending coherent and incoherent texts: Evidence from eye movement patterns and recall performance. Journal of Research in Reading, 15, 39-54. doi:10.1111/j.1467-9817.1992.tb00020.x

Wechsler, D. (1999). WISC-R: Escala de inteligencia de Wechsler para niños revisada. Madrid: TEA.

Wechsler, D. (2005). WISC-IV: Escala Wechsler de inteligencia para niños-IV. Madrid: TEA.

Wechsler, D. (2012). WAIS-IV: Escala de inteligencia de Wechsler para adultos-IV. Madrid: TEA.

White, S., Hill, E., Happé., \& Frith, U. (2009). Revisiting the strange stories: Revealing mentalizing impairments in autism. Child Development, 80, 1097-1117. doi:10.1111/ j.1467-8624.2009.013 